\title{
ESPACIALIZAÇÃO DO SETOR DE SERVIÇOS EM GOIÁS ENTRE OS ANOS DE 1990 A 2015
}

\author{
ESPACIALIZATION OF THE SERVICE SECTOR \\ IN GOIÁS BETWEEN 1990 AND 2015
}

\author{
ESPACIALIZACIÓN DEL SECTOR DE SERVICIOS EN \\ GOIÁS ENTRE LOS AÑOS 1990 A 2015
}

\author{
Tathiana Rodrigues Salgado - Universidade Federal de Goiás - Porangatu - Goiás - Brasil \\ trs.tathi@gmail.com
}

\begin{abstract}
Resumo
0 setor de serviços é, desde meados da década de 1970, o conjunto de atividades econômicas mais expressivo em termos de composição do Produto Interno Bruto (PIB) e geração de empregos formais no estado de Goiás. Nesse sentido, este artigo tem como objetivo apresentar, por meio da análise estatística, os padrões de distribuição dos estabelecimentos formais do setor de serviços em Goiás entre os anos de 1990 a 2015, período que denominamos de urbanização recente. Para atingir o objetivo, foram fundamentais os dados disponíveis nas bases de consulta do Ministério do Trabalho e Emprego (MTE), que oferecem informações sobre a distribuição espacial dos estabelecimentos e sobre o pessoal ocupado em atividades de serviços. Ao final, além da importância econômica, constatou-se uma forte tendência à concentração espacial das atividades que compõem esse setor, o que implica na formação de diferentes níveis de centralidades urbanas. Palavras-chave: Setor de serviços, espacialização, Goiás.
\end{abstract}

\section{Abstract}

Since the mid-1970s, the service sector has been the most expressive set of economic activities in the composition of Gross Domestic Product (GDP) and generation of formal jobs in Goiás. The objective of this article is to present, through statistical analysis, the distribution patterns of the formal establishments of the services sector in Goiás between the years of 1990 to 2015, a period denominated as a recent urbanization. To achieve the objectives, we use the data available on the basis of the Ministry of Labor and Employment (MTE), which provide information about the spatial distribution of the establishments and the personnel employed in service activities. Besides the economic importance, we find a strong tendency to the spatial concentration of activities that make up this sector, which involves the formation of different levels of urban centralities. Keywords: Service sector, space distribution, Goiás.

\section{Resumen}

El sector de servicios es desde mediados de la década de 1970 el conjunto de actividades económicas más expresivas en términos de composición del Producto Interno Bruto (PIB) y generación de empleos formales en el estado de Goiás. El objetivo es presentar, a través del análisis estadístico, los estándares de distribución de los establecimientos formales del sector de servicios en Goiás entre los años 1990 y 2015, período que denominamos de urbanización reciente. Para alcanzar el objetivo, fueron fundamentales los datos disponibles en las bases de consulta del Ministerio de Trabajo y Empleo (MTE), que ofrecen informaciones sobre la distribución espacial de los establecimientos y sobre el personal ocupado en actividades de servicios. Al final, además de la importancia económica, se constató una fuerte tendencia a la concentración espacial de las actividades que componen ese sector, lo que conlleva la formación de diferentes niveles de centralidades urbanas.

Palabras clave: Sector de servicios, espacialización, Goiás. 
Introdução

Neste artigo, o objetivo é apresentar a espacialização das atividades do setor de serviços em Goiás no período que abrange o início da década de 1990 até o ano de 2015. ${ }^{1}$ Esse recorte temporal, o qual se pode nomear de período de urbanização recente, é caracterizado pela acelerada inversão rural-urbana, pela fragmentação territorial - que deu origem ao estado do Tocantins -, pela tendência à maior concentração da população em poucos centros urbanos e pelo processo de metropolização verificado nas regiões do entorno de Goiânia e do Distrito Federal. ${ }^{2}$

A investigação reuniu procedimentos metodológicos como a revisão bibliográfica acerca do conceito de setor de serviços, a coleta de dados secundários sobre pessoal ocupado e número de estabelecimentos junto às bases do Ministério do Trabalho e Emprego (MTE), e o mapeamento das informações. ${ }^{3}$

A base de dados do MTE, por razão de delimitações metodológicas, compreende apenas atividades realizadas no âmbito de estabelecimentos formais, excluindo, portanto, trabalhadores de indústrias caseiras, artífices, feirantes, ambulantes etc., o que, com certeza, encobre um número considerável de atividades de serviços. Porém, mesmo com esses limites metodológicos, o levantamento é uma confiável amostragem da dinâmica econômica setorial de Goiás, e, com a análise desses dados, foi possível reconhecer algumas das particularidades do setor de serviços.

A coleta de dados também subsidiou a elaboração do material cartográfico disponível no artigo, que, por sua vez, permitiu o reconhecimento dos padrões de concentração do setor no território goiano para o período de análise.

O artigo está dividido, além dessa introdução, em três itens. O primeiro apresenta a concepção conceitual de serviços que orientou a análise dos dados. O segundo apresenta alguns aspectos gerais sobre o setor para o recorte temporal analisado. E o terceiro apresenta a espacialização das informações coletadas junto ao MTE.

Setor de serviços: um conceito para os estudos geográficos

As abordagens conceituais mais conhecidas sobre o setor de serviços são as de caráter operacional. Estas agrupam as atividades econômicas de um aparelho produtivo em três setores: o agropecuário ou primário, o 
industrial ou secundário, e o de serviços ou terciário. Cano (2012, p. 41) assim define os três setores econômicos:

i) setor primário: engloba as atividades que estão em contato direto com a natureza e cuja produção se caracteriza como de bens primários. Dele fazem parte: agricultura, pesca, silvicultura, pecuária e extração vegetal e animal.

ii) setor secundário: compreende a modificação ou a transformação de bens, por meio de processos físicos ou químicos. Dele fazem parte: indústria extrativa mineral, manufatureira ou de transformação, da construção civil e de geração de energia elétrica, produção de gás e tratamento de água e esgoto (os serviços industriais de utilidade pública).

iii) setor terciário: também chamado Setor de Serviços, não compreende a produção física propriamente dita, mas sim a prestação de serviços: atividades comerciais, transportes, seguros, serviços financeiros, previdência social, educação, saúde, serviços governamentais etc.

Essa tríplice classificação, herdada dos clássicos trabalhos de Fischer (1936) e Clark (1940), atribui ao setor de serviços um caráter residual, ou seja, todas as atividades econômicas não ligadas diretamente à produção/ extração de um bem material são englobadas no setor. A definição do setor de serviços como o grupo de atividades residuais orientou principalmente os estudos sobre desenvolvimento econômico dos países.

O caráter residual, porém, não deve ser entendido, como destaca Kon (2004), como uma parcela pouco significativa que resta de um todo, já que, modernamente, tanto nas economias desenvolvidas quanto nas subdesenvolvidas o setor de serviço representa, em média, o maior dos três setores econômicos.

A classificação dos serviços como um grupo de atividades residuais revela, na verdade, a dificuldade em definir o conjunto de ramos econômicos de naturezas tão distintas. Como destaca George (1979), a noção de setor terciário nasce mais da necessidade de classificar o grupo de atividades não diretamente produtoras, que se proliferaram como resultado da evolução tecnológica da sociedade industrial, do que pela própria essência dessas atividades. Sobre isso, Offe (1991) escreve que os serviços, assim como o modelo da "sociedade 
de serviços", são definidos por meio do que eles não são: "Nesse sentido, os serviços são geralmente entendidos como aquelas atividades econômicas que não podem ser atribuídas nem ao setor primário (agricultura, mineração), nem ao setor secundário (indústria)” (Offe, 1991, p. 13).

Outras definições pragmáticas podem ser encontradas nas contribuições de Hill (1977) e Gadrey (2001). No pensamento de Hill (1977), a ideia fundamental é a de que uma unidade econômica executa alguma atividade para benefício de outra, ou seja, uma unidade serve a outra. E para Gadrey (2001, p. 32), “uma atividade de serviço é uma operação que visa uma transformação do estado de uma realidade $\mathrm{C}$, possuída ou utilizada por um consumidor B, realizada por um prestador de serviços A a pedido de B, e com frequência relacionada a ele, não chegando, porém, à produção de um bem que possa circular economicamente independentemente do suporte de C."

Embora essas conceituações sejam práticas para os estudos de cunho econômico-estatísticos, elas são insuficientes para a compreensão da dimensão espacial dos serviços. Nesse sentido, as propostas de George (1979), Oliveira (1979) e Offe (1991), de compreender os serviços a partir de suas características funcionais, parecem-nos ser as mais adequadas para a análise geográfica que tenha o setor de serviços como objeto de estudo.

Para Oliveira (1979), o caráter primordial do setor de serviços que merece atenção é seu papel na esfera de circulação do capital. Nas palavras do autor (1979, p. 40), "esse simples reconhecimento põe de pé também outra questão: o terciário não é simplesmente aquilo que não cabe nos outros setores."

Seguindo a linha de pensamento de Oliveira (1979), é assertivo dizer que os serviços são atividades responsáveis por possibilitar a integração entre a produção e o consumo final e essa é uma função crucial em uma economia de mercado. O que, portanto, relaciona o desenvolvimento do setor à própria expansão das relações capitalistas e à ampliação dos processos de urbanização.

Entender o setor de serviço por sua natureza funcional, e não apenas como o agrupamento de atividades residuais, é útil para analisarmos o impacto no espaço das aglomerações de serviços, uma vez que os processos de distribuição e consumo ocorrem em realidades espaciais. Além disso, uma das características inerentes ao setor de serviços é a grande heterogeneidade das atividades que o compõem. Tal característica não pode ser desprezada, visto que, de acordo com George (1979), essa 
diversidade implica em diferentes zonas de influência, de fluxos de relações e diferentes efeitos de atração e polarização entre localidades, portanto, na formação de diferentes níveis de centralidades.

Da leitura de George (1979), extraímos que os serviços podem ser analisados em diferentes escalas. Um "terciário superior", funcional no nível dos conjuntos econômicos e políticos dos estados ou das grandes regiões; e um "terciário banal", ligado ao consumo local, à escala da cidade ou de uma fração de território.

Para o estudo dos serviços em espaços subdesenvolvidos, como o que realizamos, além das considerações propostas por George (1979), requer, também, como alertou Santos (2008), a consideração da desigual distribuição da renda, o que implica em impactos espaciais em nível local e regional.

Assim, consideramos, para efeito deste trabalho, a existência de dois grupos de atividades de serviços: a de serviços polarizadores e a de serviços locais. Ambos com capacidade de gerar centralidades, porém, com espacialidades distintas. Nos dois grupos vamos encontrar atividades pertencentes ao âmbito da gestão pública e pertencentes à iniciativa privada.

Os serviços polarizadores, espacialmente seletivos, são os capazes de promover interações espaciais de médio e longo alcance. Nesse grupo, podemos incluir atividades como: comércio atacadista, comércio varejista especializado e de luxo, serviços de reparação especializados, educação superior e, em alguns recortes temporais, educação média, serviços de transporte aéreo, serviços de ligação rodoviária interestadual e internacional, serviços de gestão (administração pública), além de outros serviços raros ou que não sejam de uso rotineiro e que, portanto, não justificam uma dispersão espacial, como, por exemplo, os serviços de assessoria empresarial, como marketing e propaganda e algumas especialidades médicas.

Os serviços locais, espacialmente mais dispersos, são os responsáveis pelo atendimento das populações na escala local e em geral tem contato direto com os consumidores. Nesse grupo, estão incluídas as atividades de comércio varejista de alimentos, vestuários, eletrodomésticos, artigos de uso pessoal etc., bem como o pequeno comércio atacadista destinado ao atendimento dos estabelecimentos locais, a educação fundamental, a assistência básica de saúde, os serviços de reparação não especializados, os serviços de hospedagem, entre outros.

Geograficamente, ambos os grupos podem coexistir em um mesmo espaço. Porém, a tendência é que a existência de atividades polarizadoras e a 
diversidade e a qualidade dos serviços locais reduzam-se proporcionalmente ao tamanho da concentração urbana. E, como já destacado por Santos (2008), a diferença de renda, marcante em espaços subdesenvolvidos, promoverá a coexistência de atividades de mesma natureza, mas com diferentes níveis de qualidade, cada uma influenciando um espaço específico, estruturando, dessa forma, os circuitos da economia urbana.

\section{Aspectos gerais do setor de serviços em Goiás entre 1990 a 2015}

Em 1990, a população ativa com vínculos formais de emprego em Goiás era de 434.744 mil trabalhadores, dos quais, 71,8\% empregados no setor de serviços (Brasil, 1990). Conforme é possível constatar na Tabela 1, a alta participação do trabalho terciário tornou-se uma característica da estrutura geral do emprego formal no estado.

Tabela 1 - Porcentagem de empregos formais por setor econômico em Goiás (1991-2015)

\begin{tabular}{c|c|c|c|c}
\hline Ano & Agropecuário & Indústria & Serviços' & Outros \\
\hline 1991 & 1,9 & 20,9 & 70,8 & 6,4 \\
\hline 1995 & 4,9 & 21,0 & 72,6 & 1,5 \\
\hline 2001 & 6,4 & 21,1 & 72,5 & 0,0 \\
\hline 2005 & 6,6 & 20,2 & 73,2 & 0,0 \\
\hline 2015 & 6,1 & 23,5 & 72,1 & 0,0 \\
\hline
\end{tabular}

Nota:' 0 setor de serviços inclui atividades da administração pública.

Fonte: Brasil (1991, 1995, 2001, 2005, 2015). Elaboração da autora, 2016

O que muda no decorrer dessas quase três décadas é o conteúdo interno do setor. Em 1990, com um estado recém-fragmentado, as atividades da administração pública representavam 41\% dos empregos formais em serviços, sendo que essa porcentagem havia sido igual a 36,3\% em 1988, e 42,8\% em 1989. Naquele ano, em Goiânia o serviço público representava 45,9\% dos empregos terciários e 33,5\% das ocupações formais totais. Em 25 municípios, essa categoria era responsável por mais de 90\% dos empregos em serviços com registro (Brasil, 1990).

O aumento relativo do setor público no final da década de 1980 e sua alta porcentagem no início dos anos de 1990 não resultavam, contudo, da 
ampliação do número de postos de trabalho, mas sim do desmembramento da porção setentrional do território goiano para a instalação do Estado do Tocantins, visto que os serviços públicos, historicamente, concentraram-se na porção meridional de Goiás, inclusive, este foi um dos argumentos que justificaram a criação da nova unidade federativa.

A participação da administração pública no nível de emprego formal em serviços permanece em torno de 40\% até o ano de 1996. Em 1997, essa cota cai para $35,9 \%$, em 2000 , é de $35,6 \%$ e, em 2015, a porcentagem de participação do serviço público no emprego formal reduz a 30,54\% (Brasil, 1990). Aqui, porém, cabe uma observação, os elevados valores percentuais verificados não podem ser entendidos como resultantes de uma alta participação das atividades estatais na economia ou de uma grande disponibilidade de serviços públicos. Em Goiás, esses valores, principalmente durante a década de 1990, eram sintomáticos da forte informalidade existente no setor. Conforme é possível calcular com os dados apresentados na Tabela 2, a informalidade atingia 74,6\% dos trabalhadores em serviços em 1990; 65,86\% em 2001; cai para 45,8\% em 2011, mas volta a crescer e, em 2014, é estimada em 49,3\%.

Tabela 2 - População ocupada e vínculos formais por ramos do setor de serviços em Goiás (1990-2015)

\begin{tabular}{c|c|c|c|c|c|c|c|c}
\hline \multirow{2}{*}{ Ano } & \multicolumn{2}{|c|}{ Total do setor } & \multicolumn{2}{c|}{ Comércio } & \multicolumn{2}{c|}{ Prestação de Serviços } & \multicolumn{2}{c}{ Adm. Pública } \\
\cline { 2 - 9 } & $\begin{array}{c}\text { Pop. } \\
\text { ocupada }\end{array}$ & $\begin{array}{c}\text { Vínculos } \\
\text { formais }\end{array}$ & $\begin{array}{c}\text { Pop. } \\
\text { Ocupada }\end{array}$ & $\begin{array}{c}\text { Vínculos } \\
\text { formais }\end{array}$ & $\begin{array}{c}\text { Pop. } \\
\text { ocupada }\end{array}$ & $\begin{array}{c}\text { Vínculos } \\
\text { formais }\end{array}$ & $\begin{array}{c}\text { Pop. } \\
\text { ocupada }\end{array}$ & $\begin{array}{c}\text { Vínculos } \\
\text { formais }\end{array}$ \\
\hline 1990 & 1.217 .795 & 312.050 & 285.219 & 63.953 & 816.882 & 120.204 & 115.694 & 127.893 \\
\hline 1995 & 1.805 .000 & 371.080 & 281.830 & 76.396 & 757.065 & 141.284 & 98.519 & 153.400 \\
\hline 2001 & 1.551 .505 & 529.838 & 407.717 & 127.501 & 1005.932 & 209.541 & 137.856 & 192.796 \\
\hline 2005 & 1.511 .000 & 691.593 & 529.000 & 172.695 & 867.000 & 261.754 & 163.000 & 257.144 \\
\hline 2011 & 1.805 .000 & 977.354 & 643.000 & 251.159 & 1.304 .000 & 344.557 & 207.000 & 338.436 \\
\hline 2014 & 2.119 .000 & 1.074 .400 & 666.000 & 303.640 & 1.253 .000 & 448.603 & 200.000 & 322.157 \\
\hline
\end{tabular}

Fontes: IMB (1995, 2010, 2016); Goiás (1995, 2011, 2015); Brasil (1990, 1995,

2001, 2005, 2011, 2014). Dados trabalhados pela autora2016

Nota: ${ }^{1} 0$ número de vínculos formais em administração pública é maior que o da população ocupada devido a possibilidade de um servidor poder manter mais de um vínculo. 
Na Tabela 3, é possível conferir a evolução percentual dos ramos que compõem o setor de serviços, como também observar que as atividades de comércio varejista foram as que registraram o maior crescimento relativo no período representado.

Tabela 3 - Composição interna do setor de serviços, vínculos formais em Goiás (1990-2015)

\begin{tabular}{l|r|r|r|r|r}
\multicolumn{1}{c|}{ Subsetores do IBGE } & \multicolumn{1}{c|}{1990} & \multicolumn{1}{c|}{1995} & \multicolumn{1}{c|}{$\mathbf{2 0 0 0}$} & \multicolumn{1}{c|}{$\mathbf{2 0 1 0}$} & \multicolumn{1}{c}{$\mathbf{2 0 1 5}$} \\
\hline Comércio varejista & 17,11 & 16,47 & 20,09 & 22,68 & 23,05 \\
\hline Comércio atacadista & 3,39 & 4,12 & 4,42 & 4,20 & 4,67 \\
\hline Instituições financeiras & 6,01 & 4,02 & 2,32 & 1,62 & 1,72 \\
\hline Administração técnica profissional & 8,74 & 6,52 & 9,55 & 10,55 & 11,98 \\
\hline Transportes e Comunicações & 5,91 & 7,55 & 5,96 & 5,80 & 5,87 \\
\hline Serv. de Aloj. Alimentação, reparação e manutenção & 13,62 & 8,56 & 11,19 & 10,87 & 12,36 \\
\hline Serviços Médicos, Odontológicos e Veterinários & 3,13 & 7,00 & 6,28 & 3,55 & 4,43 \\
\hline Ensino & 1,12 & 4,43 & 4,61 & 4,50 & 5,38 \\
\hline Administração Pública Direta e Autárquica & 40,98 & 41,34 & 35,59 & 36,23 & 30,54 \\
\hline Total do setor de serviços & 100 & 100 & 100 & 100 & 100 \\
\hline
\end{tabular}

Fonte: Brasil (1990, 1995, 2000, 2010, 2015). Dados trabalhados pela autora, 2016

Além do aumento da formalização nos demais ramos do setor de serviços, o encolhimento do percentual da administração pública também é resultante das políticas de privatização e liquidação de empresas públicas federais e estaduais e da adoção da prática de terceirização de funções dentro das estruturas estatais. De 1990 a 2015, foram privatizadas quatro empresas estaduais: a usina de Cachoeira Dourada, a empresa de Telecomunicações de Goiás (Telegoiás), o Banco do Estado de Goiás (BEG) e as Centrais Elétricas de Goiás (CELG). Nesse mesmo período, cinco foram liquidadas, são elas: a Caixa Econômica do Estado de Goiás (CAIXEGO), o Consórcio de Empresas de Radiodifusão e Notícias do Estado (CERNE), a Empresa de Turismo de Goiás (GoiásTur), o Consórcio Rodoviário Intermunicipal (CRISA) e a Transporte Urbano do Estado de Goiás (Transurb). Em 2017, outras quatro empresas públicas estão em processo de liquidação. 
Ainda sobre os serviços, a predominância deste setor na estrutura do emprego é paralela à terciarização do Produto Interno Bruto estadual. A Figura 1 mostra que, a partir de 1990, o setor de serviços consolida-se na dianteira da renda estadual, com uma participação sempre acima dos 50\%.

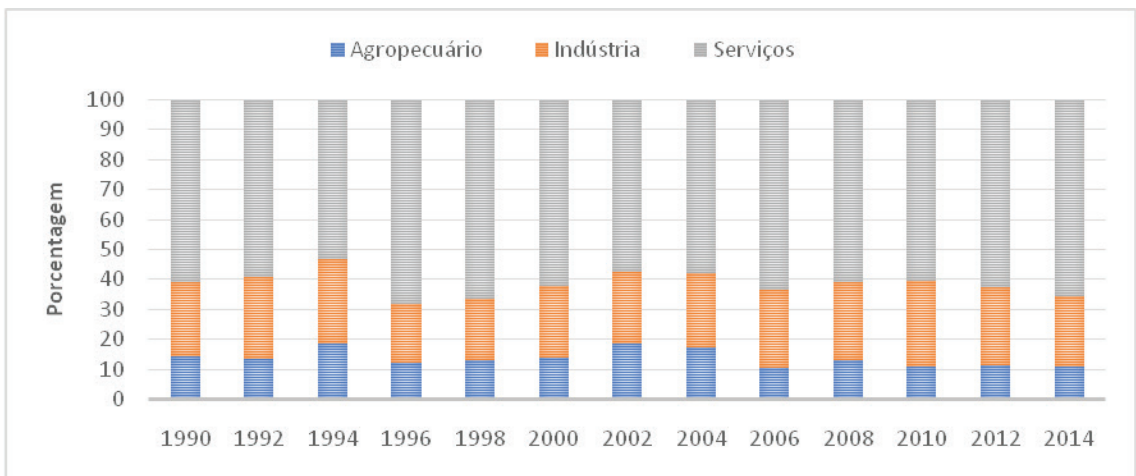

Figura 1 - Composição do Produto Interno Bruto em Goiás (1990-2014)

Fonte: SEPLAN/Sepin Gerência de Contas Regionais. Indicadores (2006, 2011, 2014).

O exame da evolução dos gêneros de serviços separadamente revela que as atividades mais relevantes do setor, em termos de valor adicionado (VA), historicamente, são as da administração pública e as comerciais. Em 1995, as participações desses dois ramos na composição do VA pelo setor foram, respectivamente, de 23 e 20\%. Em 2000, essas porcentagens são de 22 e 19\%, e, em 2014, esses valores foram de 23 e 25\%. A partir de 2005, o VA ao PIB estadual pelas atividades comerciais chega, inclusive, a superar todo o setor agropecuário (IMB, 2006, 2016). Portanto, verifica-se que o setor de serviços passa a ser o "carro chefe" da economia estadual, alicerçado, principalmente, no ramo mercantil de atendimento direto à população e da administração pública, estrutura econômica derivada da intensificação do processo de urbanização do estado verificado no pós 1988. No próximo item apresenta-se como se deu a evolução espacial desse setor.

\section{Espacialização dos estabelecimentos de serviços entre 1990 a 2015}

Em 1990, existiam em Goiás 19.191 estabelecimentos de serviços, destes, 9.901 de comércio varejista, 1.054 atacadistas, 7.928 prestadores de serviços e 308 pertencentes à administração pública (Brasil, 1990). 
Como é natural na distribuição das atividades do setor, o ramo varejista, por sua função de tornar as mercadorias disponíveis aos consumidores, é mais disperso pelo território e está diretamente relacionado às características demográficas dos lugares. Nesse sentido, a disposição do comércio varejista no início da década de 1990 mantinha, como esperado, uma alta concentração na cidade de Goiânia, como é possível verificar na Figura 2, que em 1991 aglomerava 22,9\% da população estadual e registrava uma taxa de urbanização de 99\% (IBGE, 1991), portanto, formava um grande mercado consumidor. Naquele ano a capital estadual concentrava $41,4 \%$ do comércio varejista e $85 \%$ das empresas desse ramo com mais de 100 empregados, além de ser a sede de $54 \%$ das empresas atacadistas instaladas em Goiás. Num segundo plano, estava a cidade de Anápolis, com 9,7\% dos estabelecimentos varejistas e 13,4\% dos atacadistas formalizados em Goiás (Brasil, 1990).

Em 119 municípios goianos, não havia comércio atacadista e, em outros 24 , não foram obtidos dados de estabelecimentos varejistas formais. Em termos de importância regional, mas bem atrás das duas primeiras cidades, destacavam-se, no sudoeste de Goiás, as cidades de Rio Verde e Jataí; no Sul, Itumbiara; no Sudeste, Catalão; no Norte, Porangatu e Uruaçu; e a Leste, a cidade de Luziânia.

Em relação aos estabelecimentos prestadores de serviços, 52\% estavam localizados em Goiânia, com destaque para a presença de 30\% das instituições de crédito, seguros e capitalizações, 57\% das empresas de comércio e administração de imóveis e valores mobiliários e serviços especializados e 44,6\% dos serviços médicos, odontológicos e veterinários.

As instituições de crédito, seguros e capitalizações não existiam em 58 municípios, entre eles, Goianira e Senador Canedo, no entorno de Goiânia, que já acumulavam, em 1991, respectivamente, uma população de 12.896 e 23.905 habitantes. Em 13 municípios, com faixas populacionais entre 2.000 e 4.000 habitantes, não houve registro de nenhum estabelecimento (Brasil, 1995; IBGE, 1991). Como mostra a Figura 3, essa ausência era verificada, principalmente, nas regiões nordeste, do entorno de Brasília e do médio Araguaia (oeste do estado). 


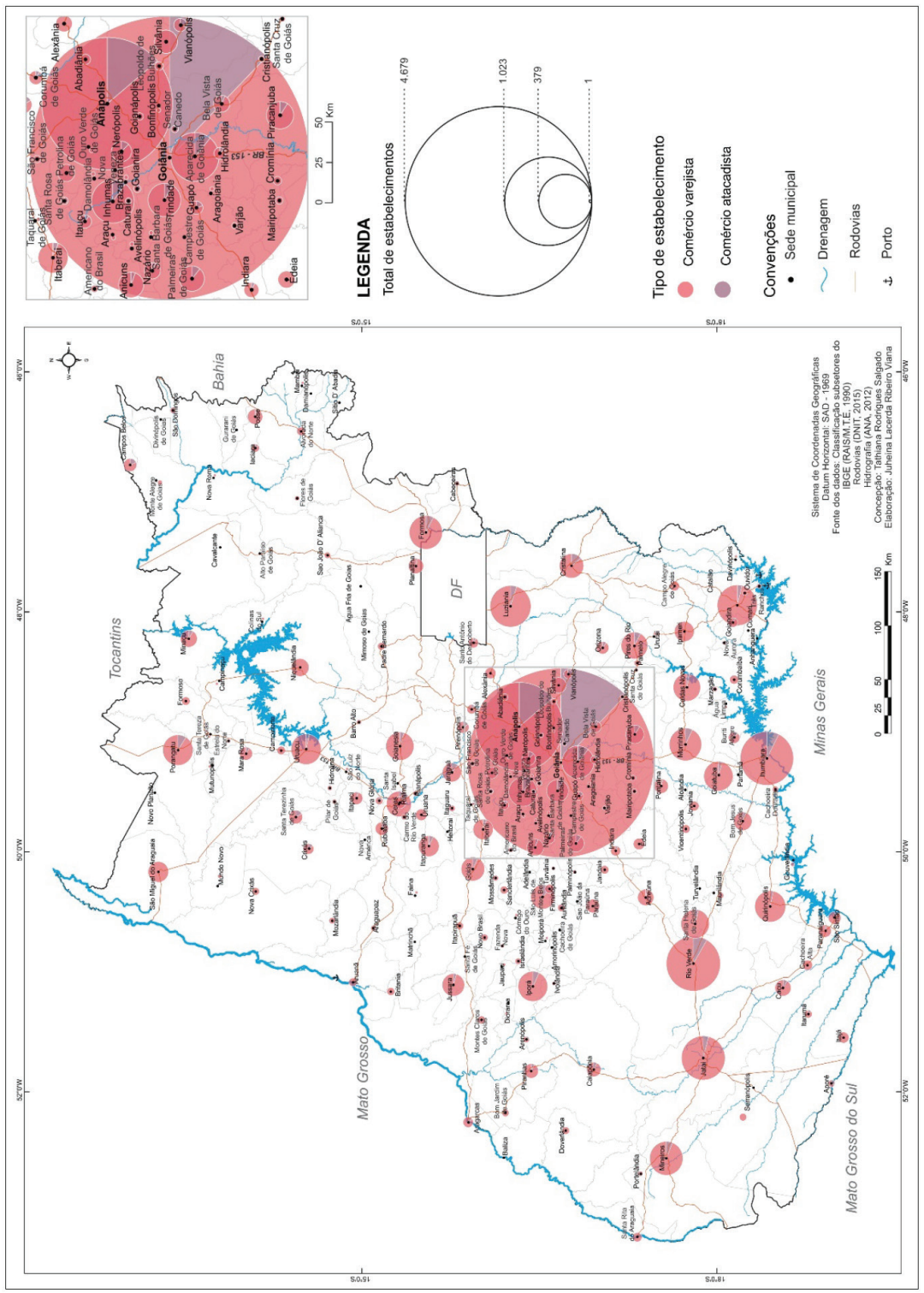

Figura 2 - Estabelecimentos comerciais formais em Goiás (1990) 


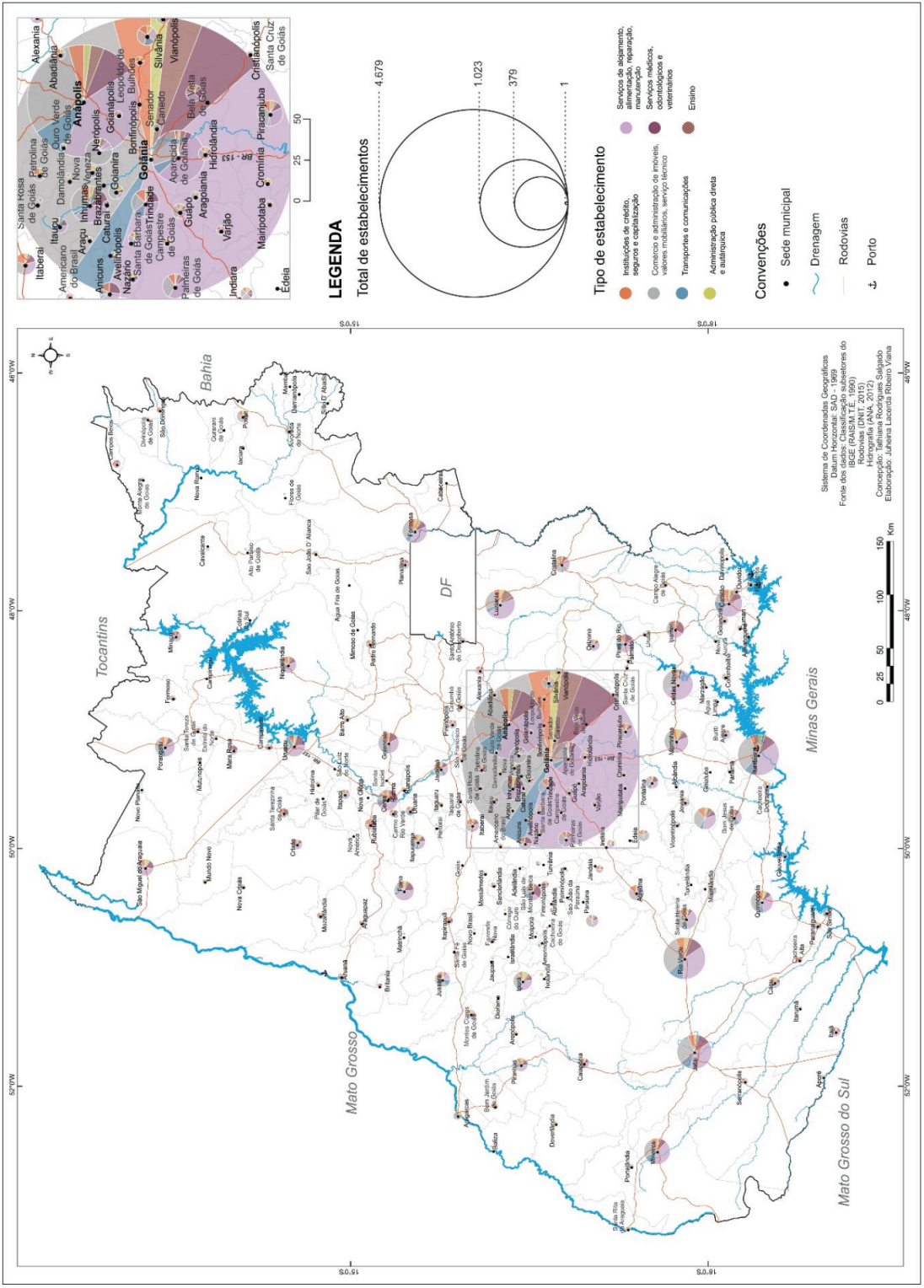

Figura 3 - Estabelecimentos prestadores de serviços em Goiás (1990) 
Em relação aos serviços médicos, odontológicos e veterinários, não foram registrados estabelecimentos formais em 95 municípios, mesmo em alguns com considerável quantitativo demográfico, como eram os casos de Santo Antônio do Descoberto (35.509 hab.), Silvânia (18.000 hab.), Corumbá (19.663 hab.) e Padre Bernardo (16.500 hab.) (IBGE, 1991). Ainda na região do entorno de Brasília, não foram registrados serviços de saúde nas cidades de Água Fria de Goiás (3.976 hab.), Água Limpa (1.937 hab.), Mimoso (3.750 hab.) e Sítio da Abadia (2.748 hab.). Em Luziânia, com uma população de 207.674 habitantes, 194.345 deles vivendo em área urbana, haviam quatro estabelecimentos de saúde (IBGE, 1991).

A cidade de Ceres, em 1990, pode ser apontada como uma exceção em relação à disponibilidade de serviços de saúde. O município - que possuía, em 1991, uma população de 22.874 habitantes, 16.951 deles no centro urbano - registrou a existência de 12 estabelecimentos, e mesmo sem apresentar evolução demográfica significativa, o número de centros de saúde sobe para 32 no ano de 1995 e 43 em 2000, um padrão bastante distinto de municípios com peso demográfico semelhante ou mesmo superior. A cidade de Porangatu, por exemplo, localizada no norte do estado e também servida pela BR-153, possuía cinco estabelecimentos de saúde, o maior deles estava registrado na faixa de 20 a 49 funcionários para o atendimento direto de uma população de 41.086 habitantes em 1991. Destes habitantes, 31.905 viviam na sede urbana. Contabilizando a população dos municípios limítrofes que não possuíam serviços de saúde, a população atendida pela cidade subia para 49.544 pessoas (IBGE, 1991).

Em 1995 o número de estabelecimentos de serviços formais sobe para 26.616, 48\% deles localizados em Goiânia. Com os dados daquele ano é possível computar ainda que a capital concentrava 15 das 21 empresas de transporte aéreo, todas as sete de pesquisa e desenvolvimento, além de $40 \%$ das empresas de transporte terrestre, 56\% dos estabelecimentos de serviços prestados diretamente a empresas, $55 \%$ dos serviços de saúde e 92,46\% dos estabelecimentos de comércio atacadista de artigos do vestuário e complementos. O comércio atacadista de máquinas, aparelhos e equipamentos para uso agropecuário só era encontrado em Goiânia, Anápolis, Rio Verde, Jataí, Ceres, Mineiros e Formosa (Brasil, 1995).

O intenso crescimento demográfico registrado nos municípios do entorno do Distrito Federal entre 1991 e 1995, que culminou na criação de mais quatro cidades, não foi acompanhado de proporcional crescimento do setor de serviços naquela região. 
Dessa forma, em 1995, 11 municípios do entorno do Distrito Federal abrigavam 11,2\% dos habitantes do Estado e 4,9\% dos estabelecimentos de serviços, predominando nesse universo o comércio varejista de alimentos, bebidas e estimulantes. ${ }^{4}$ Com exceção das cidades de Luziânia e Formosa, os demais municípios, mesmo com significativo peso demográfico, não contavam naquele ano com uma adequada disponibilidade de serviços. Esse era, por exemplo, o caso de Planaltina, que mesmo com uma população de 45.092 habitantes, não possuía estabelecimentos formais de saúde, de manutenção e reparação de veículos automotores e nem contava com comércio varejista de combustíveis. As cidades de Água Fria de Goiás, Mimoso e Vila Boa, além de não contarem com os serviços citados, não usufruíam de agências dos correios nem de estabelecimentos de ensino. O comércio varejista de móveis, iluminação e outros artigos residenciais somente eram encontrados em Formosa, Luziânia e em Cidade Ocidental. A estrutura do setor de serviços no entorno de Brasília, nos primeiros anos da década de 1990, traduz a natureza desordenada da urbanização dessa região, relacionada diretamente ao controle do solo urbano da capital federal.

Em 1995 as regióes Norte e Nordeste de Goiás também registraram pouca quantidade de estabelecimentos do setor, fato relacionado diretamente ao perfil urbano dessas duas regiões, que, respectivamente, possuíam taxas de urbanização de 76,36\% e 58,69\%, as menores do Estado, com predominância de municípios com menos de 10 mil habitantes (IMB, 1995). O perfil demográfico dos municípios dessas duas regiões, portanto, não promovia a atração de atividades mais especializadas do setor ou a aglomeração de nichos econômicos e mesmo os serviços sobre responsabilidade pública eram pouco representativos. A ausência de uma economia agrícola moderna ligada ao agronegócio e o baixo índice de industrialização das duas regiões também não favoreceram o desenvolvimento de cidades médias dotadas de boa estrutura terciária, como eram os casos de Rio Verde e Jataí, no sudoeste do Estado. E mesmo as atividades essenciais, como saúde e educação, não existiam em 14 cidades dessas regiões.

O padrão concentrado dos serviços torna-se uma característica do território goiano, conforme é possível consultar nas Figuras 4 e 5 que apresentam a espacialização das atividades comerciais e os prestadores de serviços para o ano de 2000. Naquele ano, Goiânia concentrava 21,8\% da população goiana e 43,8\% dos estabelecimentos do setor de serviços (Brasil, 2000; IBGE, 2000). 


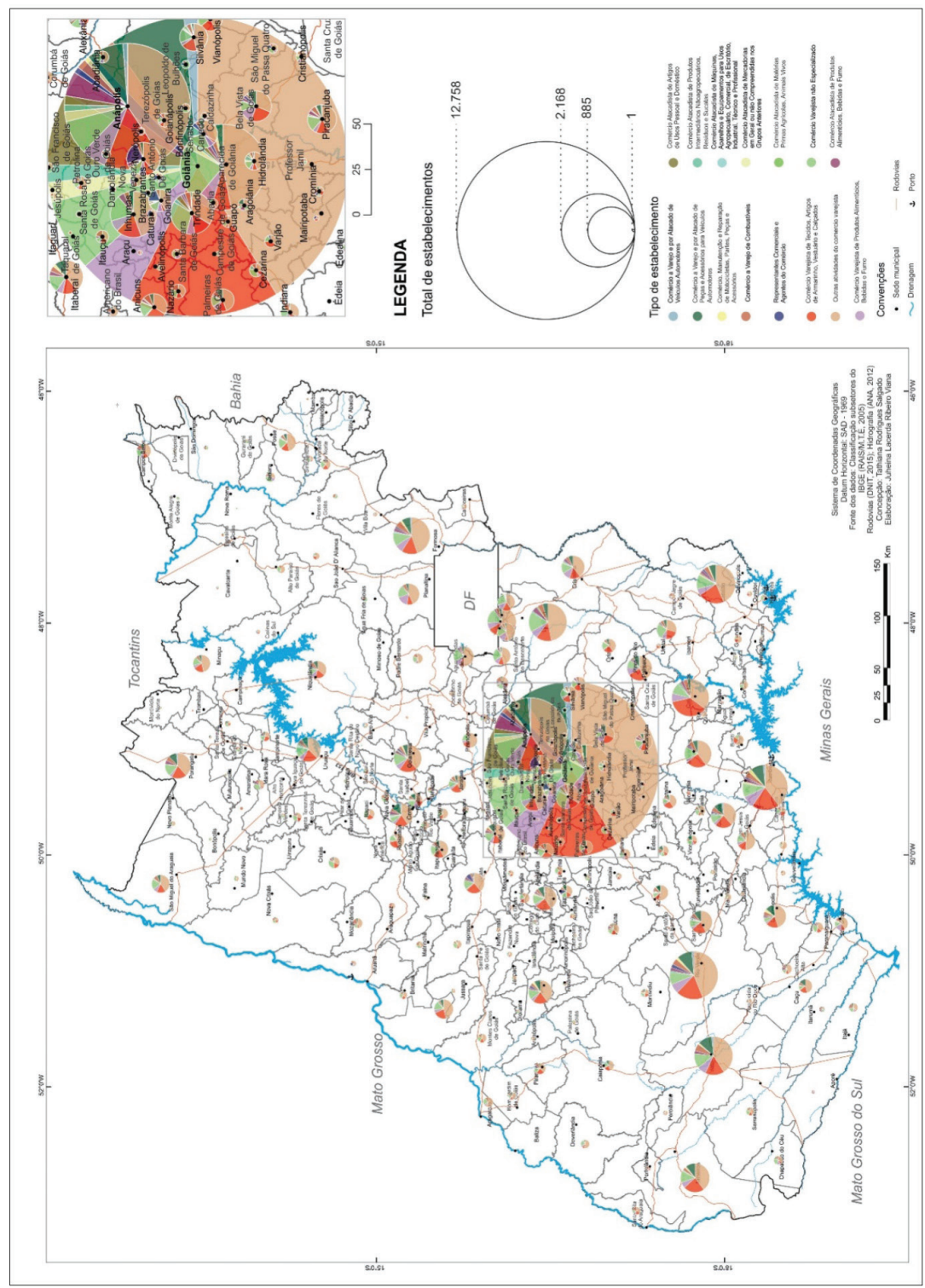

Figura 4 - Estabelecimentos comerciais formais em Goiás (2000) 


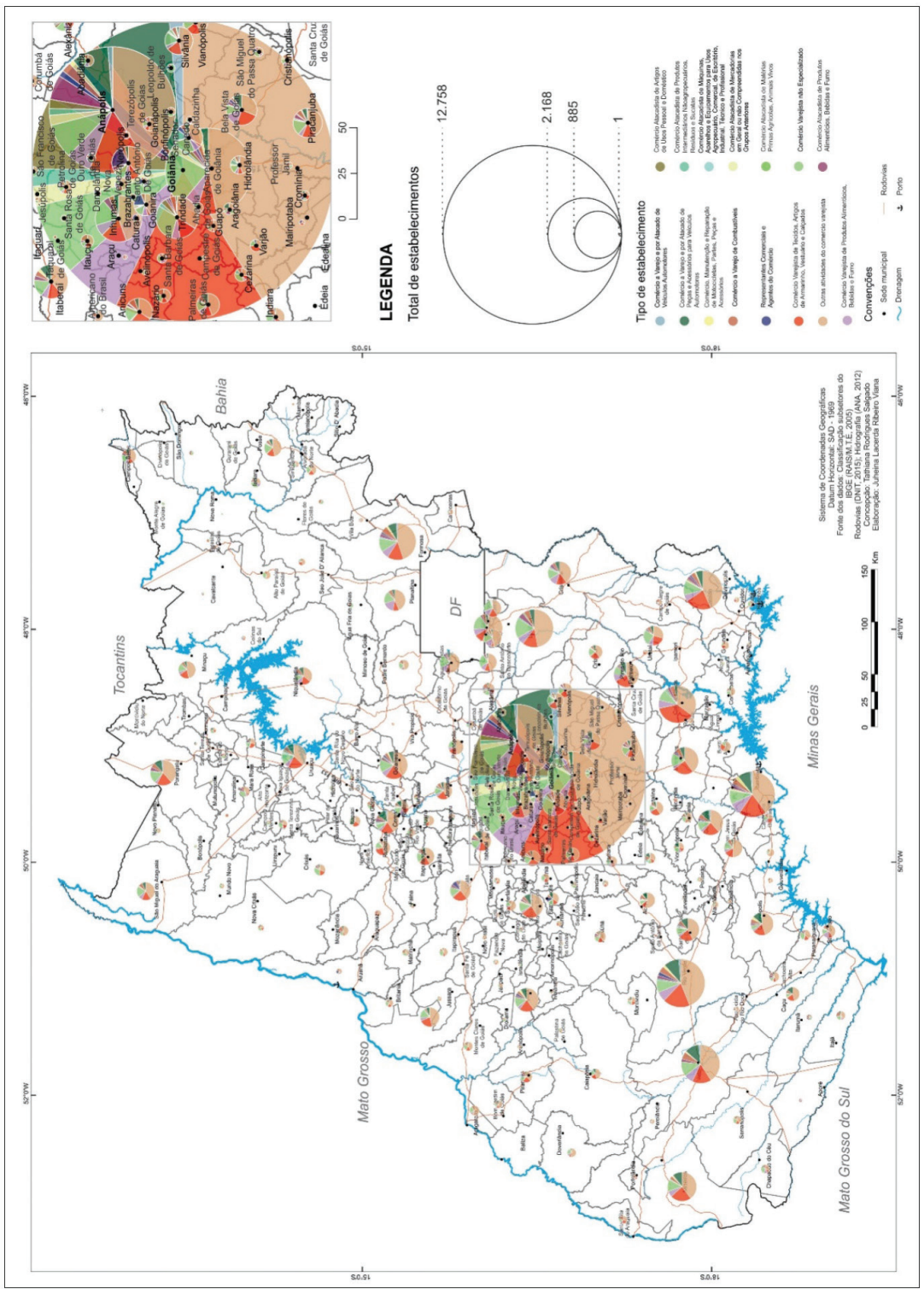

Figura 5 - Estabelecimentos formais prestadores de serviços em Goiás (2000) 
Contudo, a partir de 1995 é possível perceber uma discreta tendência à desconcentração, especialmente em favor dos municípios inseridos fora das lógicas metropolitanas, como é possível verificar na Tabela 4.

Tabela 4 - Concentração relativa dos estabelecimentos de serviço e população em Goiás (1995-2010)

\begin{tabular}{c|c|c|c|c|c|c|cccc}
\hline \multirow{2}{*}{ Ano } & \multicolumn{2}{|c|}{ Goiânia } & \multicolumn{2}{c|}{ Ent. de Goiânia1 } & \multicolumn{2}{c}{ Anápolis } & \multicolumn{2}{c}{$\begin{array}{c}\text { Ent. de } \\
\text { Brasília }^{2}\end{array}$} & \multicolumn{2}{c}{$\begin{array}{c}\text { Restante do } \\
\text { estado }\end{array}$} \\
\cline { 2 - 10 } & Estab. & Hab. & Estab. & Hab. & Estab. & Hab. & Estab. & Hab. & Estab. & Hab. \\
\hline 1995 & $48 \%$ & $23 \%$ & $2,7 \%$ & $7,4 \%$ & $8,0 \%$ & $6,0 \%$ & $4,9 \%$ & $11,2 \%$ & $36,4 \%$ & $52,4 \%$ \\
\hline 2000 & $43,8 \%$ & $21,8 \%$ & $4,3 \%$ & $9,78 \%$ & $6,6 \%$ & $5,7 \%$ & $6,8 \%$ & $15,1 \%$ & $38,5 \%$ & $47,7 \%$ \\
\hline 2005 & $40 \%$ & $21,4 \%$ & $5,6 \%$ & $11,2 \%$ & $6,0 \%$ & $5,6 \%$ & $7,6 \%$ & $17,2 \%$ & $40,8 \%$ & $44,6 \%$ \\
\hline 2010 & $38,2 \%$ & $21,6 \%$ & $6,1 \%$ & $11,3 \%$ & $5,9 \%$ & $5,5 \%$ & $8,0 \%$ & $14,8 \%$ & $41,8 \%$ & $46,8 \%$ \\
\hline
\end{tabular}

${ }^{1}$ As cidades no entorno de Goiânia são: Aparecida de Goiânia, Goianira, Senador Canedo e Trindade. ${ }^{2}$ As cidades no entorno de Brasília são: Abadiânia, Alexânia, Cabeceiras, Cidade Ocidental, Cristalina, Formosa, Luziânia, Padre Bernardo, Planaltina, Santo Antônio do Descoberto, Vila Boa e, desde 2000, os municípios de Valparaíso e Águas Lindas de Goiás.

Fontes: Brasil (1995, 2000, 2005, 2010); IBGE (2000); IMB (1995, 2005).

Entre os anos de 1995 e 2010, as regiões do entorno de Goiânia e de Brasília apresentaram ganhos percentuais de 3,4 e 3,1\% no número de estabelecimentos de serviços, embora as taxas de crescimento populacional tenham sido superiores a esses ganhos. Em contrapartida, o conjunto formado pelos demais municípios do Estado, mesmo reduzindo a participação relativa no número de habitantes, aumentou sua participação no número de estabelecimentos em 5,4\%.

No âmbito da Região Metropolitana de Goiânia (RMG), o exemplo mais ilustrativo da desconcentração dos serviços é o da cidade de Aparecida de Goiânia. Em 1995, o MTE recebeu relatórios anuais de 513 estabelecimentos, em 2000, de 1.335, em 2005, esse número sobe para 2.605 e, em 2015, chegou a 5.527. Como demonstrado por Cirqueira (2009), o crescimento demográfico da cidade, promovido pela valorização fundiária de Goiânia, estimulou o surgimento de centros comerciais, de serviços e consumo coletivo, ou seja, a formação de centralidades para o atendimento das demandas locais.

O mesmo efeito observado em Aparecida de Goiânia, mas, em menor grau, também foi verificado nas cidades de Senador Canedo, Goianira e Trindade. Portanto, mesmo nas economias metropolitanas, caracterizadas 
pela forte polarização de um município, é possível observar o movimento de dispersão das atividades do setor de serviços em direção aos municípios periféricos, já que, no caso desse setor, a tendência é que a disponibilidade, principalmente do comércio varejista, acompanhe a demanda de consumo.

É importante destacar que a dispersão dos estabelecimentos comerciais ocorreu, predominantemente, na modalidade varejista, ou como denominamos no início do artigo, nos serviços locais, uma vez que o comércio atacadista permaneceu fortemente concentrado em Goiânia, a qual, em 2010, abrigava $51,01 \%$ dos estabelecimentos dessa categoria. Entre 2000 e 2010, a cidade de Aparecida de Goiânia desponta nesse ramo de comércio, perfazendo, no período, 141 novas empresas instaladas na cidade, e totalizando, em 2010, 220 estabelecimentos, o que correspondia a 5,12\% do total estadual. Anápolis, que em 2000 concentrava 9,02\% dos distribuidores atacadistas, registra uma pequena queda em 2010 e passa a deter 8,26\% do total do Estado.

Um outro exemplo ilustrativo da dispersão do setor de serviços para o interior do estado foi a expansão dos empreendimentos comerciais do modelo shoppings centers e das grandes redes varejistas regionais e nacionais. Em 1993, era inaugurado, no trecho urbano da BR-040 em Valparaíso de Goiás, o Shopping Sul, o primeiro do entorno de Distrito Federal, remodelado em 2008 e atualmente contando com 126 lojas.

Poucos anos depois, em 1996, foi construído o primeiro shopping de Aparecida de Goiânia, o Buriti Shopping, atualmente com 200 lojas. Em 2009, também receberam esses tipos de empreendimentos as cidades de Catalão e Rio Verde. Esta última, em 2011, passou a contar com o segundo empreendimento dessa natureza, o Buriti Shopping de Rio Verde, inaugurado com 170 lojas. São inaugurados ainda, em 2012, os shoppings de Luziânia, Águas Lindas e Alexânia. Um quinto empreendimento desse gênero está previsto para a região do entorno, que deve ser construído entre as cidades de Planaltina e Formosa.

A rede Magazine Luiza, segunda maior empresa brasileira de varejo de móveis e eletrodomésticos em 2015, expandiu suas lojas pelo interior de Goiás antes mesmo de chegar à capital. Em 2004, inaugurou a primeira filial goiana na cidade de Rio Verde e, atualmente, conta com mais três lojas localizadas nas cidades de Catalão, Caldas Novas e Itumbiara. A cidade de Rio Verde também recebeu uma unidade da rede Havan, $23^{\circ}$ maior rede varejista brasileira, que possui outras filiais nas cidades de Anápolis e Valparaíso de Goiás. ${ }^{5}$ 
Também especializada no comércio de móveis e eletrodomésticos, a rede Novo Mundo, que em 2015 foi a $45^{\circ}$ maior empresa em arrecadação do ICMS (Imposto sobre Circulação de Mercadorias e Serviços) do Estado, é outra varejista goiana a optar pela expansão de suas lojas para o interior do Estado. Atualmente a rede conta com 14 lojas em Goiânia e 58 em cidades do interior.

Em 2000, havia em Goiás 111 estabelecimentos de comércio varejista de mercadorias em geral, predominando os de alimentos classificados como hipermercados: distribuídos por 42 cidades, 32 deles localizavam-se em Goiânia e 12 em Aparecida de Goiânia (Brasil, 2000). No ano de 2015, mesmo após a falência da Rede Marcos de supermercados, que possuía 10 lojas no Estado, o número de hipermercados sobe para 176, dos quais, 46 em Goiânia, e os demais distribuídos por 61 municípios (Brasil, 2015).

Nesse intervalo de 15 anos, enquanto no conjunto GoiâniaAparecida o crescimento desse tipo de varejista foi de 136\%, no restante do Estado foi de 173, 13\%. As cidades de Porangatu e Campos Belos, que não possuíam hipermercados até o ano de 2000, chegam a 2015 com duas unidades. São abertas também três unidades em cada uma das cidades de Minaçu, Inhumas e Águas Lindas. Rio Verde e Formosa ganham mais três lojas de hipermercados, totalizando, respectivamente, quatro e cinco unidades. Em Luziânia, havia três estabelecimentos em 2000 e, em 2015, esse número sobe para nove (Brasil, 2000, 2015).

Outro ramo que também se dispersou no território goiano foi o de comércio de motocicletas, peças e acessórios, inclusive com a presença em municípios com faixa populacional entre 30 a 40 mil habitantes, como são os casos de Itapuranga, Ceres, São Luís dos Montes Belos, Santa Helena de Goiás, Uruaçu, Iporá, Itaberaí, entre outros. Em 2000, essa modalidade de comércio possuía 172 estabelecimentos, dos quais, 64 em Goiânia, 18 em Anápolis e 11 em Itumbiara. Além dessas cidades, outros 29 municípios tinham revendas. Em 2015, o número desses estabelecimentos aumentou para 865, distribuídos em 122 municípios, sendo que 49,01\% das revendas situavam-se fora do conjunto Goiânia/Aparecida de Goiânia/Anápolis/Rio Verde/Itumbiara (Brasil, 2000, 2015).

A expansão desses tipos de estabelecimentos comerciais do varejo ocorreu, principalmente, em cidades com mais de 50 mil habitantes, ou com área de influência cuja população tributária é superior a 100 mil habitantes. Essa expansão para cidades com esse perfil demográfico é evidenciada pelo mapeamento dos estabelecimentos comerciais registrados em 2015, conforme é possível verificar na Figura 6. 


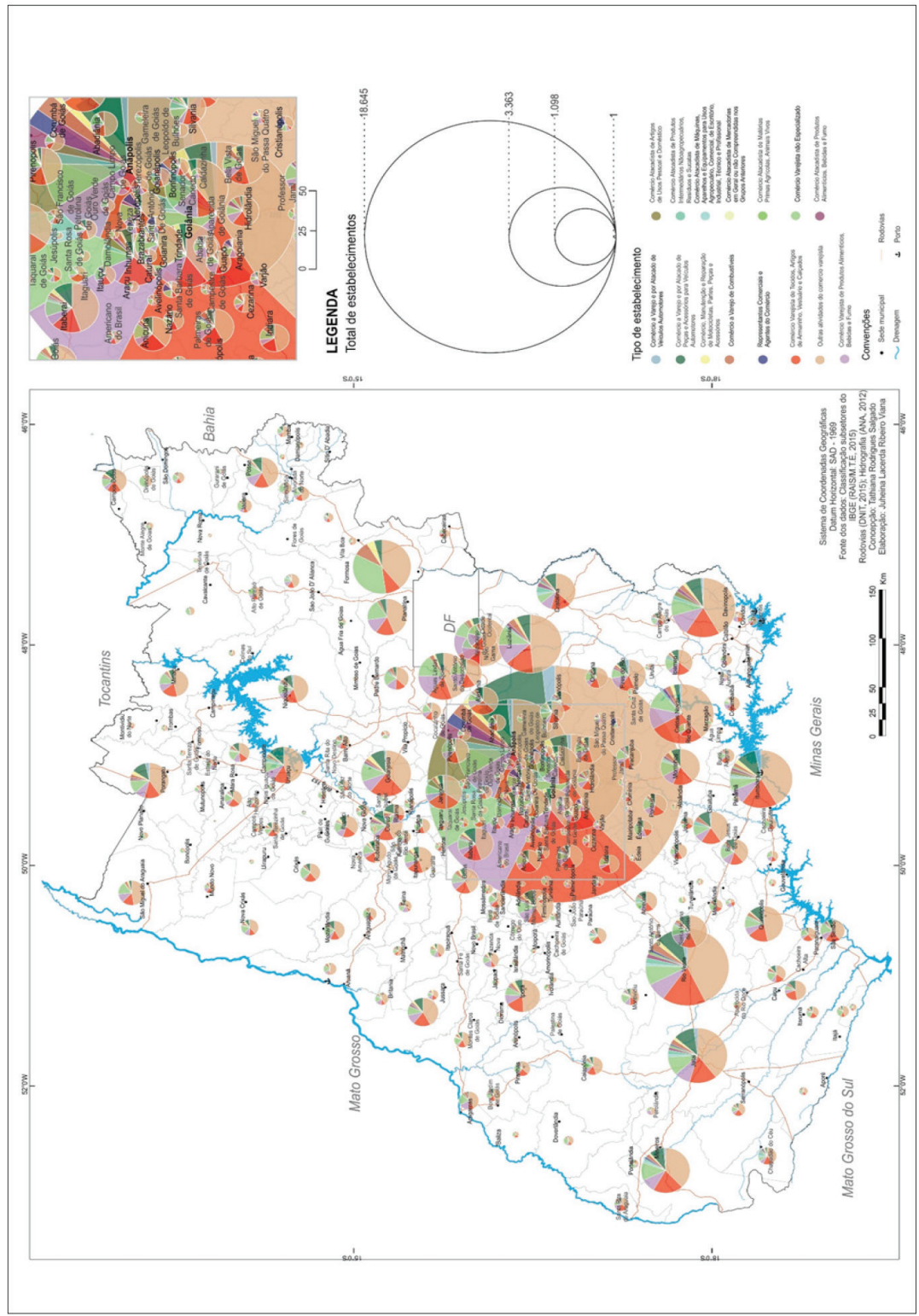

Figura 6 - Estabelecimentos formais de comércio em Goiás (2015) 
Mas, Goiânia continua a concentrar um grande polo varejista e atacadista de moda, o qual inclui os complexos da Avenida Bernardo Sayão, no Setor Fama, e dos arredores da Rua 44 e da Feira Hippie, sobretudo aos domingos, ambas situadas na região do terminal rodoviário da capital. Em 2015, Goiânia contava com 496 estabelecimentos de comércio atacadista de artigos de vestuário e complementos, o que representava 85\% dos estabelecimentos dessa natureza existentes no estado (Brasil, 2015). Essa concentração motiva um fluxo contínuo e intenso de pessoas de diversas localidades, tanto de Goiás quanto de outros estados brasileiros, principalmente oriundos do Pará, Tocantins, Rondônia, Maranhão e Minas Gerais, como comprovaram Carvalho, Wendland e Guimarães Mota (2007).

No ramo de prestadores de serviços, também se verifica, em nível estatístico, uma pequena queda de participação relativa de Goiânia no total estadual de estabelecimentos. De modo geral, ocorreu uma ampliação dos equipamentos de consumo coletivo em todas as regiões de Goiás, principalmente de estabelecimentos de ensino básico e assistência básica de saúde, ou seja, serviços de alcance local, conforme é demonstrado pela Figura 7. Em 2010, a capital goiana concentrava 42,73\% dos prestadores de serviços, enquanto, em 2015, a participação cai para 40,33\%, além de se considerar ainda que, no ano de 2000 , a queda havia sido de $8,02 \%$ (Brasil, 2000, 2010, 2015).

Porém, Goiânia mantém a concentração de serviços, principalmente em termos qualitativos ou dos denominados serviços polarizadores. Em relação aos serviços médico-hospitalares, a capital do estado reúne os grandes hospitais públicos especializados, como o Hospital de Urgências de Goiânia, o Hospital de Urgências Otávio Lage, referência em tratamento de queimaduras, o Hospital Geral, o Hospital Araújo Jorge, especializado no tratamento de pacientes com câncer, o Hospital de Doenças Tropicais, o Hospital Materno-Infantil, o Centro de Reabilitação e Readaptação e o Hospital das Clínicas, de responsabilidade da Universidade Federal de Goiás, que dispõe de um moderno centro de tratamento oftalmológico. Essa concentração demostra o papel relevante do Estado na promoção da centralidade de Goiânia nessa área do setor. 


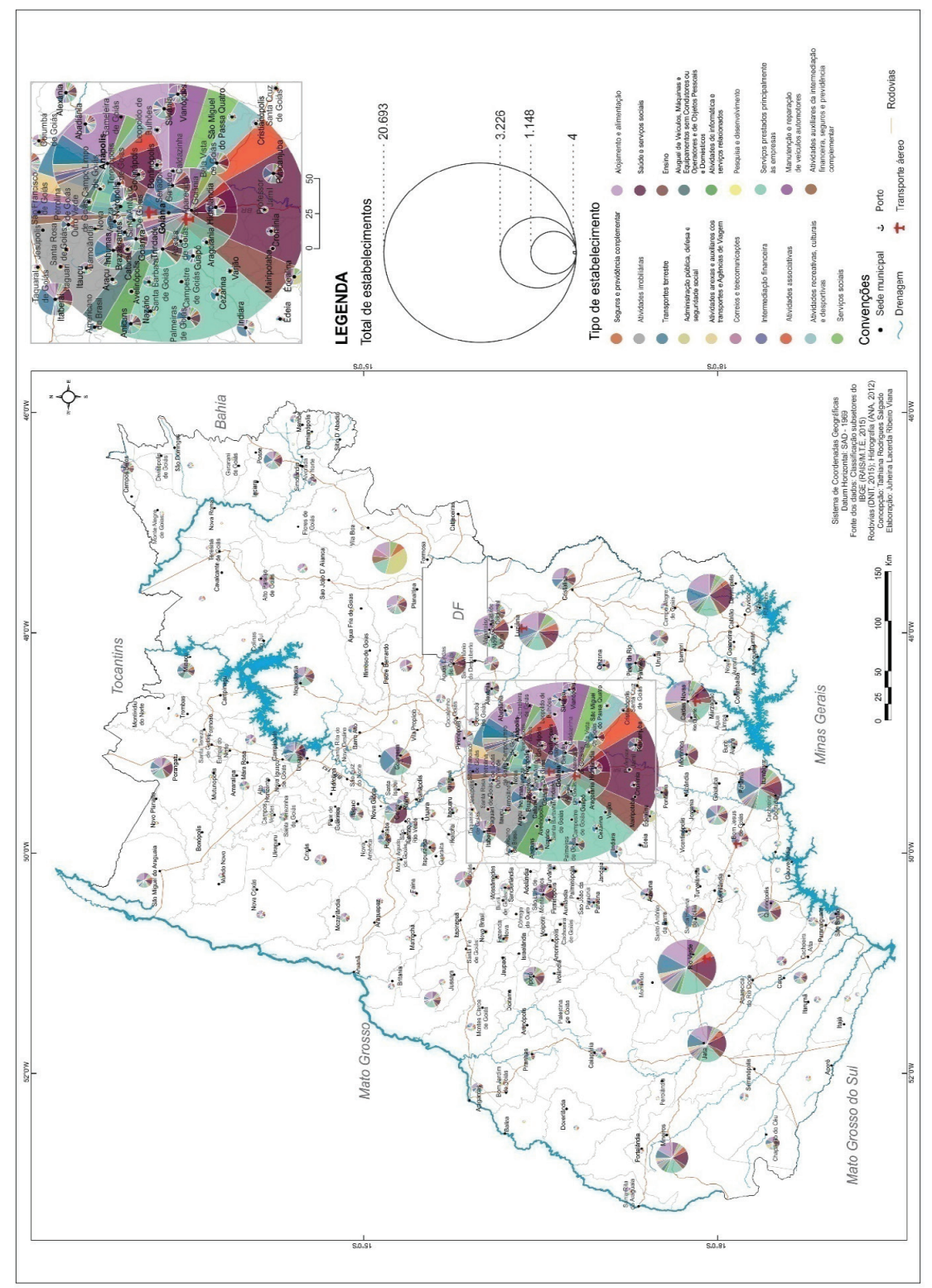

Figura 7 - Estabelecimentos formais prestadores de serviços 
Em todo estado, apenas as cidades de Anápolis, Trindade, Aparecida de Goiânia e Santa Helena de Goiás possuem também unidades do Hospital de Urgências. ${ }^{6}$ Dessa forma, todos os atendimentos de média e alta complexidade são encaminhados para a capital, o que torna Goiânia um polo de referência médico-hospitalar, de acordo com Silva (2016). Segundo o autor, ao analisar os fluxos de utilização de serviços de saúde em Goiás, apenas uma parcela pequena de municípios apresenta capacidade de serviços de saúde para atender de forma satisfatória sua população, dessa forma, o deslocamento para Goiânia acaba constituindo-se como a única possibilidade de acesso a esses serviços para muitas cidades.

Goiânia ainda demonstrou grande concentração de clínicas e hospitais particulares. Entre eles, o Hospital Anis Rassi, referência em tratamentos cardíacos, e o Hospital Renaissance, primeiro hospital privado da capital especializado em tratamentos oncológicos, além de dispor de um centro de excelência em diagnóstico, acompanhamento e tratamento das doenças do aparelho digestivo.

Em fase de vendas e implantação, o "Órion Business \& Health Complex” é um complexo de negócios e saúde construído em uma área nobre de Goiânia e planejado para abrigar um hospital com 140 leitos ambulatoriais, 40 leitos de UTI e centro cirúrgico de 14 salas, além de apresentar um centro clínico com diversas especialidades, um hotel com 260 unidades de dormitórios, um centro de negócios direcionados a empresas de advocacia, engenharia e administração e um shopping, com instalação inicial de 59 lojas.

Em relação ao ensino superior, Goiânia dispõe da presença dos dois maiores campus da Universidade Federal de Goiás (UFG), de quatro campus da Pontifícia Universidade Católica de Goiás (PUC) e dois campus da Universidade Estadual de Goiás (UEG), além de contar com um do Instituto Federal de Goiás e de várias faculdades particulares, que oferecem um grande leque de cursos de graduação e pós-graduação. Na Figura 6, é possível observar a distribuição espacial das principais atividades de serviços existentes na cidade de Goiânia para o ano de 2016.

Entre os serviços mais dispersos na escala estadual, em 2015, estavam os relacionados a alojamento, alimentação e correios, e os mais concentrados, os de transporte aéreo - levando-se em conta que o transporte aéreo regular de passageiros somente estava disponível em Goiânia -, os de atividades imobiliárias e os relacionados a seguros e previdência complementar. 
Na Figura 7, anteriormente apresentada, ainda é possível perceber que, nas cidades margeadas por rodovias, desenvolvem-se, principalmente, os serviços vinculados a demandas dessa modal de transporte, como o comércio varejista de combustíveis e o de serviços de manutenção de veículos automotores, além dos serviços de alimentação e alojamento. Vejamos os exemplos das cidades de Itumbiara e Porangatu: na primeira, a soma dos estabelecimentos dedicados a atividades de transportes terrestres, manutenção e reparação de veículos automotores e de alojamento e alimentação representavam 40\% do total municipal de prestadores de serviços, enquanto, na segunda cidade, essa porcentagem é de 33\%. Arrais et al. (2016), ao investigar os impactos territoriais da BR-153 no centro-norte brasileiro, destacam que o perfil das cidades, ao longo da rodovia, está plenamente articulado com uma rede de serviços de suporte às atividades de circulação dentro do território goiano-tocantinense.

\section{Considerações finais}

As atividades que compõem o setor de serviços, por sua natureza funcional, são essenciais para o funcionamento da economia de mercado, incluindo a manutenção das condições de reprodução da força de trabalho. Como bem destacaram Santos e Silveira (2001, p 167), "hoje não basta produzir. É indispensável pôr a produção em movimento, pois agora é a circulação que preside à produção. Os fluxos daí decorrentes são mais intensos, mais extensos e mais seletivos.” E como lembra Oliveira (1979), o setor de serviços é por excelência o que abriga os processos de circulação, distribuição e consumo das mercadorias e do próprio capital.

À vista disso, entendemos que o padrão de localização das atividades do setor possui forte relação com a organização socioespacial do território, uma vez que a concentração, em termos quantitativos e qualitativos, está diretamente vinculada à promoção de fluxos de mercadorias, capitais, consumidores e trabalhadores; à formação de centralidades e, consequentemente, ao processo de estruturação das redes urbanas regionais.

Com a observação do comportamento do setor de serviços em Goiás, a partir da classificação e espacialização dos estabelecimentos formais, foi possível notar que, após o início da década de 1990, houve o desenvolvimento qualitativo e a diversificação do setor, com a ampliação 
dos ramos mais modernos, representados pelos serviços financeiros, grandes redes de comércio varejista e serviços especializados nas áreas de tecnologia e especialidades médicas de alta complexidade, além da ampliação da rede de comércio atacadista no estado.

Todavia, a análise a nível municipal revelou que, como é próprio do desenvolvimento de espaços organizados a partir do modo de produção capitalista, há uma concentração diferencial dos estabelecimentos de serviços pelo território goiano, o que implica na formação de diferentes níveis de centralidades urbanas. Nesse sentido, verificou-se a fraqueza de muitos municípios goianos em atender as necessidades de consumo de suas populações, inclusive os serviços locais, mesmo nos recortes temporais mais atuais, o que acarretou no acúmulo de várias funções urbanas relacionadas aos serviços, sobretudo do comércio especializado e atenção a saúde de média e alta complexidade, ou seja, os serviços polarizadores, na cidade de Goiânia, historicamente privilegiada pelos capitais públicos e privados.

Goiânia, desde sua fundação, foi um exemplo de centro comercial e financeiro e de serviços, que além de deter o privilégio de ser a sede administrativa do Estado - recebendo, dessa forma, maior volume de recursos públicos em infraestrutura e concentrando funções urbanas relacionadas aos serviços públicos - atraiu fluxos populacionais, que se traduziu no aumento de demanda por consumo e investimentos de capitais nas atividades de comércio e prestação de serviços, drenando, portanto, recursos do espaço agrário e dos centros urbanos de menor porte, fortalecendo seu setor de serviços. E mesmo com a relativa dispersão do setor verificada a partir da segunda metade da década de 1990, a capital continua a concentrar, principalmente, em termos qualitativos, os estabelecimentos do setor de serviços do estado de Goiás.

\section{Notas}

1 Uma leitura sobre a evolução e a espacialização do setor de serviços em Goiás para o período de 1940 a 1980 pode ser encontrada em Salgado (2017).

2 Em Goiás, a taxa de urbanização que era de $69,8 \%$ em 1988 , sobe para $80,7 \%$ em 1991, e, em 2010, essa porcentagem eleva-se a 90,28\%. Entre 1991 e 2010, o número de centros urbanos com mais de 50 mil habitantes passou de sete para 18. Esses mesmos centros reuniam 53\% da população urbana do estado em 1991, e, em 2010, essa parcela sobre para 66\% (GOIÁS, 1995; IBGE, 2010). 
3 Os dados disponibilizados pelo MTE, por meio de plataforma on-line, são os resultados da tabulação das informações da Relação Anual de Informações Sociais (Rais). A Rais é um relatório de informações socioeconômicas solicitadas anualmente pelo MTE às pessoas jurídicas e aos empregadores brasileiros. Para consulta dos dados, acesse: <http://bi.mte. gov.br/bgcaged/inicial.php>.

4 Abadiânia, Alexânia, Cabeceiras, Cidade Ocidental, Cristalina, Formosa, Luziânia, Padre Bernardo, Planaltina, Santo Antônio do Descoberto e Vila Boa.

5 De acordo com o ranking das 50 maiores varejistas do Brasil em faturamento, elaborado em 2015 pela editora da revista Exame e publicado em 12 de agosto de 2016. Disponível em: <http://exame.abril.com.br/negocios/ as-50-maiores-varejistas-do-brasil-em-faturamento-em-2015/>.

6 Dados disponíveis no site da Secretaria Estadual de Saúde. Disponível em: <http:// www.saude.go.gov.br/>. Acesso em: 15 jan. 2017.

\section{Referências}

ARRAIS, T. A. A produção do território goiano: economia, urbanização, metropolização. Goiânia: Editora UFG, 2013.

ARRAIS, Tadeu A.; ALENCAR, Diego Pinheiro; VIANA, Juheina Lacerda. O grand tour da educação goiana: economia, eficiência e fracasso do diálogo sobre as organizações sociais. Élisée: Revista de Geografia da UEG. Porangatu, v. 5, n. 1, p. 9-28, jan./jul. 2016.

BRASIL. Ministério do Trabalho e Emprego. Programa de Disseminação das Estatísticas do Trabalho. Relação Anual de Informações Sociais (RAIS). Brasília, DF, 1990. Disponível em: <http://bi.mte.gov.br/bgcaged/inicial.php>. Acesso em: 13 jan. 2016.

. Ministério do Trabalho e Emprego. Programa de Disseminação das Estatísticas do Trabalho. Relação Anual de Informações Sociais (RAIS). Brasília, DF, 1991. Disponível em: <http://bi.mte.gov.br/bgcaged/inicial.php>. Acesso em: 13 jan. 2016.

. Ministério do Trabalho e Emprego. Programa de Disseminação das Estatísticas do Trabalho. Relação Anual de Informações Sociais (RAIS). Brasília, DF, 1995. Disponível em: <http://bi.mte.gov.br/bgcaged/inicial.php >. Acesso em: 15 jan. 2016.

.Ministério do Trabalho e Emprego. Programa de Disseminação das Estatísticas do Trabalho. Relação Anual de Informações Sociais (RAIS). Brasília, DF, 2001. Disponível em: http://bi.mte.gov.br/bgcaged/inicial.php. Acesso em: 13 jan. 2016.

. Ministério do Trabalho e Emprego. Programa de Disseminação das Estatísticas do Trabalho. Relação Anual de Informações Sociais (RAIS). Brasília, DF, 2005. Disponível em: <http://bi.mte.gov.br/bgcaged/inicial.php>. Acesso em: 13 jan. 2016. 
. Ministério do Trabalho e Emprego. Programa de Disseminação das Estatísticas do Trabalho. Relação Anual de Informações Sociais (RAIS). Brasília, DF, 2010. Disponível em: http://bi.mte.gov.br/bgcaged/inicial.php. Acesso em: 13 jan. $/ 2016$

. Ministério do Trabalho e Emprego. Programa de Disseminação das Estatísticas do Trabalho. Relação Anual de Informações Sociais (RAIS). Brasília, DF, 2011. Disponível em: http://bi.mte.gov.br/bgcaged/inicial.php. Acesso em: 13 jan. $/ 2016$.

. Ministério do Trabalho e Emprego. Programa de Disseminação das Estatísticas do Trabalho. Relação Anual de Informações Sociais (RAIS). Brasília, DF, 2014. Disponível em: http://bi.mte.gov.br/bgcaged/inicial.php. Acesso em: 13 jan. $/ 2016$.

- Ministério do Trabalho e Emprego. Programa de Disseminação das Estatísticas do Trabalho. Relação Anual de Informações Sociais (RAIS). Brasília, DF, 2015. Disponível em: <http://bi.mte.gov.br/bgcaged/inicial.php>. Acesso em: 25 mar. 2016.

CANO, W. Introdução à economia: uma abordagem crítica. São Paulo: Unesp, 2012.

CARVALHO, G. L.; WENDLAND, S. M.; GUIMARÃES MOTA, A. M. O impacto da feira hippie no setor turístico-hoteleiro de Goiânia. Boletim Goiano de Geografia, Goiânia, v. 27, n. 3, p. 29-48, abr. 2007.

CIRQUEIRA, J. V. Fragmentação da metrópole: constituição da RMG e suas implicações no espaço intraurbano de Aparecida de Goiânia. 2009. 174 f. Dissertação (Mestrado em Geografia) - Instituto de Estudos Socioambientais, Universidade Federal de Goiás, Goiânia, 2009.

CLARK, C. A. The Conditions of Economic Progress. London: Macmillan \& CO, 1940.

FISCHER, A. G. The Clash of Progress and Securiity. London: Macmillan \& CO, 1936.

GADREY, J. Emprego, produtividade e avaliação do desempenho dos serviços. In: SALERMO, M. S. (Org.). Relação de Serviço: produção e avaliação. São Paulo: Senac, 2001.

GEORGE, P. Populações ativas. São Paulo: DIFEL, 1979.

GOIÁS (Estado). Goiás em Dados. Goiânia: Secretaria de Planejamento e Coordenação/Superintendência de Estatística, Pesquisa e Informação, 1995. Disponível em: <http://www.imb.go.gov.br/down/Godados1995.pdf>. Acesso em: 6 maio 2016.

Goiás em Dados. Goiânia: Secretaria de Planejamento e Coordenação/ Superintendência de Estatística, Pesquisa e Informação, 2011. Disponível em: <http://www.imb.go.gov.br/down/Godados 2011.pdf>. Acesso em: 5 jan. 2016.

. Goiás em Dados. Goiânia: Secretaria de Planejamento e Coordenação/ Superintendência de Estatística, Pesquisa e Informação, 2015. Disponível em: <http://www.imb.go.gov.br/down/Godados 2015.pdf>. Acesso em: 10 jun. 2016. 
.SEPLAN/Sepin Gerência de Contas Regionais. Indicadores (2006, 2011, 2014). Disponíveis em: <http://www.imb.go.gov.br/>. Acesso em: 15 abril/2016.

IBM. Instituto Mauro Borges. Produto Interno Bruto do Estado de Goiás. Goiânia, 2006. Disponíveis em: <http://www.imb.go.gov.br>. Acesso em: 15 abril2016.

HILL, P. On Goods and Services. The Review of Income and Wealth, n. 4, p. 315-338, dez. 1977. IBGE. Instituto Brasileiro de Geografia e Estatística. Censo demográfico de 1991. 1991. Disponível em: <https://biblioteca.ibge.gov.br/bibliotecacatalogo?id=782\&view=detalhes $>$. Acesso em: 22 abril 2016.

. Censo demográfico de 2000. 2000. Disponível em: <https://www.ibge. gov.br/estatisticas-novoportal/sociais/educacao/9663-censo-demografico-2000. html?edicao $=9771 \& \mathrm{t}=$ sobre $>$. Acesso em: 16 abril 2016.

. Censo demográfico de 2010. 2010. Disponível em: <https://ww2.ibge.gov. br/home/estatistica/populacao/censo2010/default.shtm>. Acesso em: 17 abril 2016.

IMB. Instituto Mauro Borges. Estatísticas Municipais (Séries Históricas). 1995.

. Produto Interno Bruto do Estado de Goiás: 2010. Goiânia, 2010.

. Produto Interno Bruto do Estado de Goiás: 2014. Goiânia, 2016.

KON, A. Economia de serviços: teoria e evolução no Brasil. Rio de Janeiro: Elsevier, 2004.

OFFE, C. O crescimento do trabalho nos serviços: quatros explicações sociológicas. In: . (Org.). Trabalho e sociedade: problemas estruturais e perspectivas para o futuro da sociedade do trabalho. Rio de Janeiro: Tempo Universitário, 1991.

OLIVEIRA, F. de. O terciário e a divisão social do trabalho. Petrópolis, RJ: Vozes (Estudos Cebrap), n. 24, 1979.

SALGADO, T. R. Setor de Serviços e urbanização pretérita. Élisée: Revista de Geografia da UEG, Porangatu, v. 6, n. 2, p. 29-57, jul./dez. 2017.

SANTOS, M. O espaço dividido: os dois circuitos da economia urbana dos países subdesenvolvidos. São Paulo: Edusp, 2008.

SANTOS, M.; SILVEIRA, M. L. O Brasil: território e sociedade no início do século XXI. 13. ed. Rio de Janeiro: Record, 2001.

SILVA, C. M. Centralidade e Mobilidade: uma análise dos deslocamentos dos pacientes do SUS em Goiás. Goiânia: Editora da UFG, 2016.

Tathiana Rodrigues Salgado - Graduada, mestre e doutora em Geografia pela Universidade Federal de Goiás. Professora da Universidade Estadual de Goiás, campus da cidade de Porangatu. ORCID: https://orcid. org/0000-0002-2656-4862. 